\title{
Learning from Jesus' Wife: What Does Forgery Have to Do with the Digital Humanities?
}

\author{
James F. McGrath
}

\section{Introduction}

Early in the summer of 2016, interest in the papyrus fragment known as the Gospel of Jesus' Wife had begun to wane. Then investigative journalist Ariel Sabar published an article unveiling a great deal of truly fascinating evidence that he had uncovered, related not only to the Gospel of Jesus' Wife itself, but also the person who we can now say was almost certainly responsible for the forgery. The article told of connections with sex and pornography, scams and financial catastrophes, which made the real story behind the text seem even more sensational than the contents of the papyrus fragment itself. ${ }^{1}$ Since then, still other new texts have come to light and made news headlines, including purported additional Dead Sea Scrolls, and what has been hailed as the oldest papyrus mentioning Jerusalem. ${ }^{2}$ Israeli prime minister Benjamin Netanyahu appealed to the latter within days of the news of the fragment first appearing, as he responded to a proposed UNESCO declaration about the purported lack of ancient Jewish connection to the Temple Mount. Meanwhile, the Jordanian Department of Antiquities finally offered its assessment that the lead codices, touted by David Elkington as dating from the time when Jesus was alive, are modern fakes, a conclusion that most discussion of them online had already drawn. ${ }^{3}$ These and many other examples illustrate how the work of scholarship on ancient history intersects with contemporary concerns,

1 Sabar, Ariel, "The Unbelievable Tale of Jesus' Wife," The Atlantic, July/August 2016, <https:// www.theatlantic.com/magazine/archive/2016/o7/the-unbelievable-tale-of-jesus-wife/ 485573/>, accessed on 10.04.19. On the broader context - the question of whether the historical figure of Jesus was married - see Le Donne, Anthony, The Wife of Jesus: Ancient Texts and Modern Scandals, London: Oneworld, 2013.

2 Moss, Candida, Baden, Joel, “Is Israel's Big New Find for Real?" The Daily Beast, 11th of June 2016, <http://www.thedailybeast.com/articles/2016/11/o6/is-israel-s-big-new-find-a-hoax. html>, accessed on 10.04.19.

3 Jordan Times, "Antiquities agency chief says Jordan Codices fake", Jordan Times March 9th, 2017, <http://www.jordantimes.com/news/local/antiquities-agency-chief-says-jordan-codi ces-fake>, accessed on 10.04.19. 
ranging from debates about celibacy in the Catholic Church to ongoing tensions in the Middle East. A successful forgery can make an enormous difference, but so too can an unsuccessful one - or one that is made intentionally with a view to it being exposed, since a forgery that claims to conveniently support some political or religious claim can further undermine it in the eyes of the public when the truth is revealed. ${ }^{4}$ In addition to cyberwarfare and robotics, we may well also see forgery of antiquities increasingly used as an ideological weapon in the years to come. Mistaking a forgery for an authentic ancient artifact can also undermine public confidence in academic expertise. Whatever the motives happen to be, forgeries and fakes will undoubtedly continue to appear on the antiquities market, and scholars of antiquity will still have their work cut out for them.

The case of the so-called Gospel of Jesus' Wife provides an excellent test case around which to ask about the role of the digital humanities in not only the exposing but also the creation of forgeries. Our focus here will not be on the text itself, or the specific arguments for and against its authenticity, which have been rehearsed elsewhere, but rather on the principles and methods which characterized academics' reception of and engagement with the text and with one another in discussing the text. The scholarly work on this particular papyrus fragment illustrates how scholarship is and can be done in the context of today's technology and social media, as well as highlighting both the potential and pitfalls of these methods. But the incident also provides opportunities for insights into the trajectories that forgery, the detection of forgery, and the digital humanities are likely to take moving forward into the future. The height of the discussion about this text is just far enough in the past that we can feel like we have enough information on the basis of which to comment, and yet not so far that it reflects a different technological setting, or something likely to be considered merely "old news".

It is appropriate to begin with what we can ascertain about the creation of the Gospel of Jesus' Wife, before moving on to the exposure thereof as a forgery. The Digital Humanities is not simply synonymous with the drive towards open access, and the placement of both primary texts and scholarship online where

4 Bak, János M., Geary, Patrick J., Klaniczay, Gábor (eds.), National Cultivation of Culture: Manufacturing a Past for the Present. Forgery and Authenticity in Medievalist Texts and Objects in Nineteenth-Century Europe, 1, Leiden: Brill, 2014. 
the public as well as scholars can access them. However, digitization and access are major concerns of ours, and without continued progress and developments in these areas, the Digital Humanities in the full sense would be severely diminished. It may thus be disheartening to reflect on the fact that the Digital Humanities makes forgery easier. We saw this in the case of the Gospel of Jesus' Wife, in which the forger used Michael Grondin's interlinear of the Gospel of Thomas, which he had made available online, as well as utilizing Herbert Thompson's edition of the Qau Codex, which is in the public domain, to produce the accompanying forgery of part of the Gospel of John. ${ }^{5}$ Images and transcriptions of manuscripts made available online will continue to provide forgers with things they can duplicate. This trend is likely to increase and expand in the future. It is likely that $3 \mathrm{D}$ analyses and descriptions of genuine artifacts will soon be fed into ${ }_{3} \mathrm{D}$ printers to produce fake artifacts, whether exact replicas of the original or ones modified to appear even more significant and valuable. At present, such objects would be unlikely to pass authenticity tests, but this may change in the future. ${ }^{6}$ Either way, if objects get news coverage before being tested, the public might be influenced by sensational headlines, never reading rebuttals that appear less prominently later. The very discussion of the issues related to the dating of the Gospel of Jesus' Wife and its identification as a forgery can potentially serve as an instruction manual for future forgers, helping them to produce more convincing fakes, as for instance

5 Askeland, Christian, “A Lycopolitan Forgery of John's Gospel," NTS 61:3, July 2015, 314-334, Askeland, Christian, "A Fake Coptic John and Its Implications for 'The Gospel of Jesus's Wife', TynBul 65, 2014, 1-10.

6 Rabinowitz, Adam, "The Work of Archaeology in the Age of Digital Surrogacy," in: Olson, Brandon R., Caraher, William (eds.), Visions of Substance: ${ }_{3} D$ Imaging in Mediterranean Archaeology, Grand Forks: The Digital Press @ The University of North Dakota, 2015, 29-30 suggests that we may not need to worry. See, however, the example of the Van Gogh replica that matched the brush strokes, frame, and even hand-written notes and labels on the reverse of the canvas of the original, using Fujifilm's process of Reliefography, as described in Liszewski, "3D Printing and Scanning." This was followed by the creation of a new painting created using software that analyzed the characteristics of the famous artist's works, as reported on by Brown, Mark, "New Rembrandt' to be unveiled in Amsterdam," The Guardian, $<$ https://www.theguardian.com/artanddesign/2016/apr/05/new-rembrandt-to-be-unveiledin-amsterdam>, accessed <http://www.jordantimes.com/news/local/antiquities-agencychief-says-jordan-codices-fake $>$. On other ethical issues related to the ${ }_{3} \mathrm{D}$ printing of replicas of antiquities, see Schroeder, Caroline, "On Palmyra and ${ }_{3}$ D Modeling Cultural Heritage in the Middle East," Early Christian Monasticism in the Digital Age 6/12/2016, <http://earlymonasti cism.org/2016/o6/12/on-palmyra-and-3d-modeling-cultural-heritage-in-the-middle-east/>, accessed on 10.04.19, <http://www.jordantimes.com/news/local/antiquities-agency-chiefsays-jordan-codices-fake>, and Bond, Sarah, "The Ethics Of ${ }_{3}$ D-Printing Syria's Cultural Heritage," Forbes, 22nd of September 2016, <https://www.forbes.com/sites/drsarahbond/ 2016/og/22/does-nycs-new-3d-printed-palmyra-arch-celebrate-syria-or-just-engage-in-digi tal-colonialism/>, accessed on 10.04.19. 
when scholars have pointed out how forgers can recycle old papyrus and fake ancient ink. This potential for our work to be used by forgers might dishearten scholars, but it is in no sense an argument against the Digital Humanities. The same printed volumes that have served scholars in the past have also been available to forgers and con artists for them to use. It is inevitable that any products, digital or otherwise, which facilitate scholarship will be open to potential use and misuse by those seeking to profit through deceit. It is not a solution to restrict materials behind paywalls or limit their circulation online, as though that would prevent forgers from getting hold of them.

Moreover, the Digital Humanities has good reason to be working to develop precisely the technologies that forgers can (and inevitably will) utilize. Scholars will develop them for different ends, and will call them different things. But there are legitimate reasons to create high quality convincing replicas or facsimiles of texts and artifacts, such as allowing the originals to be preserved safely in optimal storage conditions, while simultaneously being visible to the public on display in the museum - or even in multiple museums simultaneously. The facsimiles of the Dead Sea Scrolls on display in the Shrine of the Book are not "forgeries," although if they had been produced in precisely the same way but with different intention, and sold to an unwitting customer for an inappropriate price as though genuine, they would be placed in that category. ${ }^{7}$ Forgery has to do with the reason why an object is created, and what is done with it, and not its physical characteristics, composition, or date in and of themselves. ${ }^{8}$ Facsimiles and replicas are important positive contributions that the Digital Humanities can and should be working to provide, even beyond the longstanding tradition of presenting facsimiles in museum exhibits (as well as their gift shops). Imagine if every archaeology and every ancient language classroom could have access to replicas of incantation bowls, $3 \mathrm{D}$ printed from clay, or manuscript facsimiles printed on papyrus. Imagine if producing such items became simple and inexpensive enough that one could give each class multiple collections of pottery or parchment fragments to work with, and for the next semester, simply print new ones. Imagine if museums

7 Another example of the blurring of such lines is the bust of Nefertiti. Stierlin, Henri, Le Buste de Néfertiti. Une imposture de l'égyptologie?, Gollion: Infolio, 2009, suggests that this famous object began in an effort to create ${ }_{3} \mathrm{D}$ rendition of the ancient queen, but was later mistaken for an authentic ancient artifact.

8 See further Lenain, Thierry, "The Narrative Structure of Forgery Tales," in: Kila, Joris, Balcells, Marc (eds.), Heritage and Identity: Cultural Property Crime : An Overview and Analysis of Contemporary Perspectives and Trends, 1, Leiden: Brill, 2014esp. 39, who emphasizes that forgery in the strict sense, by definition, has primarily to do with the story behind the creation of the object, rather than its physical characteristics. See also Ehrman, Bart D., Forgery and Counterforgery: The Use of Literary Deceit in Early Christian Polemics, Oxford University Press, 2012. 
could more easily create replicas of important texts and artifacts for display, allowing them to be touched and handled by visitors, because they can now easily be replaced when they wear out. These are all legitimate and important positive goals within the framework of the Digital Humanities. The fact that they will inevitably be used by forgers does not make them less appropriate. But it does necessitate that scholars reflect on, discuss, and plan courses of action to respond to such use, and ideally that we do so before and while developing the technology, rather than only later, being proactive rather than allowing ourselves to be caught off guard when the technology is being put to troubling uses.

Most of the above points pertain to the artifacts themselves. As far as the content of manuscripts and inscriptions are concerned, some of the same Digital Humanities projects that have the potential to supply forgers with convenient resources on the internet also have the potential to help reveal forgeries for what they are. This is significant in and of itself, since it is important to the academic study of history that frauds and fakes be exposed, lest our reconstructions of the past be influenced by inauthentic objects and accounts. On the other hand, as academics reflect on the reasons why the digital resources that serve the needs of forgers cannot at present just as quickly lead to their exposure, it brings into focus some of the larger challenges confronting the Digital Humanities, and the role of academics in efforts to combat forgery, as well as in relation to media coverage of purported new finds.

One of the major shifts in the Digital Humanities in recent years is the transformation of a digital desert's economy of scarcity into a deluge that threatens to drown us with more raw data than we could ever hope to tame. ${ }^{9}$ The overabundance of material - for instance, the sheer number of manuscripts and out of print books that have been scanned and made available - means we cannot manage it, cannot ever realistically hope to become personally acquainted with it all. This might appear to give the upper hand to the forgers: they need only find an obscure, neglected text online and copy it, and the likelihood of their being detected is minimal. This is not, however, discouraging news. It simply highlights the need to continue working to develop tools that can engage in optical character recognition of manuscripts in ancient languages such as Syriac, Greek, Hebrew, Aramaic, Coptic, and others with which we work. If the results of OCR scanning of older printed texts is imperfect, the

9 Michelson, David A., "Syriaca.org as a Test Case for Digitally Re-Sorting the Ancient World," in: Clivaz, Claire, Dilley, Paul, Hamidović, David (eds.), Ancient Worlds in Digital Culture, Leiden: E.J. Brill, 2016, <http://discoverarchive.vanderbilt.edu/handle/1803/8344>, accessed on 10.04.19, 59-66. 
results of using OCR on handwritten texts will be all the more so. There will be a need for extensive proofreading of any such scans, work that will itself take decades if not longer. However, as educators who investigate plagiarism cases know, it does not take a precise match with an entire text in order for one to be able to trace copied material to its source. All it takes is verbatim reproduction in some sections, for searches on randomly-selected excerpts to produce positive results. We might therefore hope that one day, as digitization projects continue and OCR technology improves, whenever someone approaches an academic with a fragment of papyrus that they claim to have found, this could be followed on the spot by a Google search, which might fairly quickly suggest that the work too precisely matches another fragment or an online edition of a text, or reveal something else that should give a scholar pause. Of course, Google and most other widely-used search engines are commercial enterprises, and the results they provide may not be what are needed for these sorts of undertakings, even if OCR technology is developed that can accurately recognize ancient scripts, and even if the digitized manuscripts or transcriptions are online and not behind a paywall. Moreover, just as profit motivates forgers, the lack of profitability in the study of most ancient texts may prove to be a disincentive for corporations, keeping them from pursuing technology that would be useful in exposing forgeries for what they are.

It should go without saying that merely matching a known manuscript's contents does not make a new discovery a forgery, nor less valuable. It can be exciting for academics when additional copies of already-known works are found, regardless of how many we already have. However, such additional copies may not be especially valuable in financial terms. For forgeries to be profitable, therefore, it is not enough for them to appear to stem from a particular time and place. Their content needs to appear striking and unique. Nevertheless, the production of something unique yet convincing must inevitably build on existing knowledge of language and of texts. We saw in the case of the Gospel of Jesus' Wife that the forger drew heavily on known texts, making relatively minor modifications so as to make the contents more sensational. Just like students who plagiarize but change a few words, submitting the Gospel of Jesus' Wife to something like TurnItIn might have raised red flags immediately - if that database had included or searched online sources such as Grondin's Gospel of Thomas website. Once again, the point is not that this particular commercial tool would be the best one to rely on in such instances. But the same or a similar approach to maintaining and searching databases of texts might nonetheless prove useful in detecting some instances of forgery, just as tools like TurnItIn or even a Google search can detect some but by no means all instances of academic dishonesty. 
Working to produce replicas, and to develop better and better technologies for doing so, is in the best interest of the education of students and the general public. The same is true for the making available of photos of the ancient artifacts and manuscripts themselves. Participation in the development of technologies and tools of these sorts is also likely to better situate us to recognize when others have used those same resources in an attempt to deceive and/or profit. ${ }^{10}$ If those technologies become so advanced that it ceases, at some point in the future, to be possible to distinguish genuine ancient artifacts from forgeries, that will deal a serious blow to our prospects for learning new things about the past. But that technology will be developed, if indeed it can be developed, regardless of whether scholars participate in the process. And that will not change the situation for historians as radically as might first appear. Even today, the authenticity of unprovenanced artifacts is often uncertain. ${ }^{11}$ In a future with even more advanced technology to create forgeries, just as in the present day, the most important element will be for academics to do their best to be the first to find ancient texts and other objects, and to document their discovery in a way that vouchsafes their authenticity. For, as Caroline Schroeder writes, "a thorough accounting of provenance is the only means of proving the authenticity of the fragment."12

If the mindset of the public (as well as many scholars and scholarly organizations) were to shift so that only texts and other artifacts whose provenance is clear were taken seriously, some of the issues related to forgery might no longer arise. However, the very fact that forgeries have occurred and continued to occur highlights the underlying problem, namely that human beings are not always trustworthy. For this reason, the question will still need to be asked whether and to what extent we can trust archaeologists, papyrologists, museum curators, and others who claim to have acquired items and maintained collections in a manner that safeguards their authenticity. In a context in which our ability to trust, and perhaps the appropriateness of trust, has been called into question or seriously undermined, scholars and the public will con-

10 See e.g. Bernhard, Andrew, "Postscript: A Final Note about the Origin of the Gospel of Jesus' Wife," NTS 63:2, 309-316.

11 See Schroeder, Caroline, "Institutional Responsibilities," Early Christian Monasticism in the Digital Age 6/23/2016, <http://earlymonasticism.org/2016/o6/23/on-institutional-re sponsibilities-and-on-gender-final-thoughts-on-the-g-of-jesus-wife/>, accessed on 10.04.19, 3-22, on the way replication blurs the distinction between the real and the simulated. in the Digital Age 6/16/2016, <http://earlymonasticism.org/2016/o6/16/provenance-prove nance-provenance/>, accessed on 10.04.19. 
tinue to hope that scientific tests will offer somewhat objective results that can settle matters, when assertions and even written documentation may not. ${ }^{13}$

\section{$3 \quad$ Learning to Detect Forgeries}

In a post on the American Schools of Oriental Research blog, Heather Parker addresses the point just made, as well as the second major point which now follows. She writes, ${ }^{14}$

Forging an ancient document is difficult and requires expertise in several fields and a variety of resources. However, the same resources produced by scholars who study genuinely ancient texts are available to everyone. Handbooks and reference volumes on the languages and scripts of the Bible and its world are available in libraries and increasingly online. Software and digital fonts for replicating script forms are also readily available, as well as are volumes on the archaeology, history, and culture of the ancient world, complete with maps of archeological sites. The forger's job is easier than ever.

Often forgers will inscribe a fake text on a genuine artifact such as a potsherd, stone object, or piece of papyrus. Such artifacts can often be stolen with relative ease while excavating - legally or illegally - ancient archaeological sites. Looters have ready illegal access to many archaeological sites throughout the Middle East where limited resources or political upheaval prevent adequate protection. Economic conditions also make the illegal antiquities trade particularly lucrative.

[I]n the past, forgeries could be readily detected by scientific methods. For example, any ancient object recovered from the ground, as well as any ancient inscription written on such an object, will be covered with a patina - a film that accrues on an object over time as the result of various chemical processes, such as oxidation and calcification. Patinas can be analyzed spectroscopically to determine their precise chemical makeup,

13 See Meadows, David, "Oxyrhynchus and the First Apocalypse of James: Collection History Just Got Murkier," Rogue Classicism 12/13/2017, <https://rogueclassicism.com/2017/12/13/ oxyrhynchus-and-the-first-apocalypse-of-james-collection-history-just-got-murkier/>, accessed on 10.04.19, for an example of questions being raised about a papyrus whose reputation and status most would consider solid; also Nongbri, "Provenance."

Parker, Heather Dana Davis, "Forging Ancient Texts," The Ancient Near East Today, vol. 4, $\mathrm{n}^{\circ}{ }_{10}$, October 2016, <http://www.asor.org/anetoday/2016/10/o6/forging-ancient-texts/>, accessed on 10.04.19. 
and whether they include any modern elements. However, forgers, with the proper means, who wish to bolster the authenticity of their products, can now forge patinas using ancient organic materials that would pass various scientific rests, such as carbon-14 dating. Ancient organic materials can also be used to produce "ancient" inks with which to create inscriptions. As the resources for producing forgeries improve, forgers are better equipped than ever to defraud the unwary.

Parker's article was worth quoting at length because it highlights a number of key points that we have learned in connection with the Gospel of Jesus' Wife (as well as other cases). But most importantly, it is important to note the things, which, even though they are true about the Gospel of Jesus' Wife and its creator, are not the things which demonstrated it to be a forgery.

As Caroline Schroeder wrote in commenting on Sabar's Atlantic article, "A lot of the article focuses on the background of the owner of the fragment. This information is all important for understanding the story. I think it's dangerous, however, to imprint upon the fragment whatever 'sketchiness' or 'skeeviness' we attribute to the owner. Does the fact that the owner was involved in pornography necessarily mean the fragment is inauthentic? No. Does his knowledge of Coptic prove inauthenticity? No. Do his financial troubles prove it was a forgery? No."15 One can add to this list the fact that the text was poorly written, and that it seemed to be a pastiche of material from other Gospels. As was pointed out early on, these same things are true of numerous authentically ancient texts. Some of those texts are so familiar to us, as is their extensive reproduction of earlier source material, that it is really quite shocking that any scholar would propose such features as unambiguously indicative of a modern forgery. ${ }^{16}$

Some scholars' immediate reaction to the fragment was that it is "too good to be true." But we ought never to say such things, and especially not say them as though they demonstrate forgery. ${ }^{17}$ If the Gospel of Philip had come to light

15 Schroeder, Caroline, "More on Social Networks and Provenance," Early Christian Monasticism in the Digital Age 6/16/2016, <http://earlymonasticism.org/2016/o6/16/social-net works/>, accessed March 19th, 2018.

16 See McGrath, James F., "Slow Scholarship : Do Bloggers Rush in Where Jesus' Wife Would Fear to Tread?" in: Burke, Tony (ed.), Fakes, Forgeries, and Fictions: Writing Ancient and Modern Christian Apocrypha: Proceedings from the 2015 York Christian Apocrypha Symposium, Eugene: Wipf and Stock, 2017, 326-340.

17 Heide, Martin, "The Moabitica and Their Aftermath: How to Handle a Forgery Affair with an International Impact," in: Lubetski, Meir and Edith (eds.), New Inscriptions and Seals Relating to the Biblical World: Society of Biblical Literature archaeology and biblical studies, Williston: Society of Biblical Literature, 2012, 193-241. 
today for the first time via an antiquities dealer, one would have been inclined to say the same thing. A text that entices the reader by saying that "Jesus loved Mary and kissed her frequently on the..." only to have a convenient hole in the manuscript that can be filled with any sort of lurid imaginings one wishes? Isn't this "too good, too sensational, to be true"? Yet the manuscript is genuinely ancient-although it can still be considered an ancient forgery, since it was not in fact authored by the apostle Philip. ${ }^{18}$

There is thus a wisdom that we not only can but we need to learn from the case of the Gospel of Jesus' Wife, about how one demonstrates forgery, and how and whether one can do so in the present day. Carl Sagan popularized the phrase that "extraordinary claims require extraordinary evidence."19 It can be argued that a find which would radically change our understanding of history ought to be held to a higher standard of evidence than a more mundane discovery. But be that as it may, the contents of the Gospel of Jesus' Wife did not really constitute an extraordinary claim. It might, if authentic, have represented another example of the kind of viewpoint found in the Gospel of Philip. But that hardly merits the sensation that arose over the fragment.

And so perhaps one tool in our arsenal as we seek to combat forgery is to work to make the public, through the media, more aware of the rather extraordinary things we already find in authenticated ancient texts. Some of those things are sensational, noteworthy, and interesting enough that, on the one hand, forgers will either have to ratchet up the kind of shocking content they include in their creations in an attempt to make them valuable, costing them credibility in the process. On the other hand, we can hope that the public might understand that there is no reason to treat a 4 th-century text saying Jesus had a wife as especially newsworthy, which would lessen the financial value of a forgery of this sort, and thus undermine one motivation to produce something like it. To be sure, we should be under no illusion that a greater public awareness of authentic ancient texts will make forgeries go away - and we could be forgiven for pessimistically thinking that informing and persuading the public presents greater hurdles than determining the authenticity of a manuscript.

Many of the points made above have more to do with the prevention of forgeries than their detection, but the latter will never cease to be an important skill. The investigation of the case of the Gospel of Jesus' Wife highlighted the fact that there are limits to what existing scientific techniques such as Carbon 14 dating or Raman Spectrography dating can prove, since ancient materials

18 Ehrman, Bart D., Forgery and Counterforgery, 14, 19-20, 30-32, 43, 531.

19 He says this, for instance, in the 1980 Cosmos episode "Encyclopedia Galactica." 
can be recycled..$^{20}$ That procedure of forgery - destroying ancient writing to make something else with either the ink or papyrus - is disturbing to contemplate in and of itself. Not only is a new object that sows historical confusion produced by the process, but genuine historical knowledge is destroyed as well, sacrificed in an effort to produce something that is fraudulent, but hoped to be more financially valuable. Future technology, however, may help us in our efforts to detect forgeries, beyond what they are currently capable of. For example, computer analysis may be able to identify common features and patterns in forgeries that the human eye and mind might not. The infrared and laser scanning technology that can now allow us to read a scroll without opening it, or one that is badly charred, may also detect aspects of modern forgeries that are currently being missed, and do so in a less invasive or destructive manner than is currently possible. If a technology in its current form cannot provide such insights, the next generation of the technology may. Moreover, even features visible to the naked eye may not be recognized as significant in detecting forgery until computer correlation of large data sets recognizes certain patterns. Yet this should not be an automated process. Automatic plagiarism detectors have failed to discern formatting and footnoting that made the agreement between two sources legitimate. Those detectors are helpful when they are used wisely by human beings. It is important not to jump to conclusions the way some did when the papyrus of the Gospel of Jesus' Wife was found to be ancient, since that result alone was not sufficient to determine whether the text written on the papyrus was also ancient.

As it turns out, however, we should not be too pessimistic about the value even of our current technologies and their usefulness in detecting forgeries, or about the value of newly-available texts and objects to serve as inspiration for the development of new tools of investigation. New technologies for detecting forgery were developed in order to study the Gospel of Jesus' Wife. Karen King has said that "the most significant development' resulting from the papyrus was the formation of the Ancient Ink Laboratory at Columbia University and that lab's subsequent discovery of a nondestructive technique to date ancient inks. Director of the Ancient Ink Laboratory Jim T. Yardley said the lab created a 'totally unprecedented' method of dating manuscripts by analyzing tiny ink samples with a 'scanning electron microscope." When these new tests were carried out in conjunction with the more traditional method of Carbon

20 Compare Goler, Sarah, et al. "Characterizing the Age of Ancient Egyptian Manuscripts through Micro-Raman Spectroscopy." Journal of Raman Spectroscopy 47.10, 2016, 1185-1193 with Krutzsch, Myriam, and Ira Rabin, "Material Criteria and their Clues for Dating," NTS 61:3, July 2015, 356-367. 
14 dating, the truth emerged: Yardley said, "The ink is from $200 \mathrm{AD}$, while the carbon 14 test says the document is from $700 \mathrm{AD}$. The age of the ink could be younger than the substrate, but it can't be older." ${ }^{21}$ And so in this case, scientific methods did confirm the conclusions of investigative journalism and humanistic forms of analysis and argumentation..$^{22}$ Moreover, the simple fact that inks take much longer to dry completely than the typical forger will be willing to wait, makes some classic methods for detecting forgeries still very useful. ${ }^{23}$ What we can hope for from future technology is not only better ways of detecting forgeries, but also less invasive and less expensive ways of undertaking the same kinds of verifications and analyses that are currently in use. ${ }^{24}$ The takeaway message is that sometimes one method on its own may provide a clear answer, but in many cases, and perhaps most cases, a combination of approaches will be needed either to get at the truth, or simply to make the conclusions drawn by one approach more sound and secure.

\section{$4 \quad$ Learning Collaboration and Cooperation}

Academics sometimes express frustration about the media, in response to sensationalized headlines or misrepresentation as our nuanced explanations are edited into sound bites. Yet in the case of the Gospel of Jesus' Wife, journalists, professional scholars, graduate students, and interested laypeople all played an important role in carrying out the necessary investigations. Without the contribution of the kind of detective work that characterizes investigative journalism, we would not have as much clarity about this matter as we do. In his article for The Atlantic mentioned at the beginning of this chapter, Ariel

$21 \quad$ Bennett, Bonnie K., ' 'Gospel of Jesus' Wife' Researcher Says Frenzy Distracts from Larger Issues," The Harvard Crimson, 11th of November 2016, <http://www.thecrimson.com/arti cle/2016/11/11/papyrus-christianity-divinity-school/>, accessed March 19th, 2018. The scientific work referred to here is published as Goler et.al., "Characterizing the age." investigation, see Schroeder, Caroline, "Gender and the Academy Online: The Authentic Revelations of the Gospel of Jesus' Wife," in: Burke, Tony (ed.), Fakes, Forgeries, and Fictions: Writing Ancient and Modern Christian Apocrypha: Proceedings from the 2015 York Christian Apocrypha Symposium, Eugene: Wipf and Stock, 2017, 304-313.

Bell, Suzanne, How to Identify a Forgery: A Guide to Spotting Fake Art, Counterfeit Currencies, and More, New York: Skyhorse Publishing, 2013, 78.

24 The issue of how expensive tests are is mentioned in Burleigh, Nina, Unholy Business: A True Tale of Faith, Greed and Forgery in the Holy Land, New York: Smithsonian Books/ Collins, 2008,186, citing Jean-Baptiste, Patrick, L'affaire des fausses reliques: enquête au coeur des trafics de vestiges bibliques, Paris: Albin Michel, 2005. 
Sabar directly quotes from the American Association of Museums' Guide to Provenance Research, which in turn alerts academics and museum employees that investigation of provenance "is not unlike detective work." This point was also highlighted by Liv Ingeborg Lied in a conference paper about the Gospel of Jesus' Wife:

The first point that deserves our attention, is the very fact that it was a journalist, using journalistic methods, that provided the last piece of the puzzle. Much work had already been done by scholars, but the provenance piece was still wanting. In later interviews, Sabar refers specifically to the importance of his experience as a news reporter for solving the case. He points out that journalistic methods, such as knocking on doors, talking to strangers, and following paper trails proved successful (Radio West - 8:21). He also notes that this is not something scholars would normally do. Scholars are used to working in the environment of the university, in archives and libraries, etc., but the methods he had used to track down Fritz and solve the case of the provenance of the fragment is a 'blind spot' in the repertoire of scholarly methods. ${ }^{25}$

Lied goes on to highlight that (1) "it was the combination of humanistic and journalistic methods that solved the case"; (2) it was the journalistic approach, which ultimately persuaded Karen King; and (3) the scientific methods were the least successful in setting the matter to rest. This last point is important, and reinforces our earlier point that matters of authenticity-testing should not be automated, while also highlighting the other side of that same coin: just as agreement with existing text does not automatically demonstrate forgery (any more than Matthew's agreement with Mark, for instance, makes the former a "forgery"), so too the antiquity of papyrus and ink can no longer be relied upon to safeguard the antiquity of the text written on that papyrus with that ink. Perhaps one day soon we may be able to use technology to recognize characteristics that distinguish forgeries made with recycled materials. But until then (and perhaps even then), we will need to employ historical/humanistic and journalistic/investigative methods along with scientific ones, and to allow the

25 Lied, Liv Ingeborg, "Media Dynamics and Academic Knowledge Production: Tracing the Role of the Media in the Gospel of Jesus's Wife Saga," paper read at the conference Fragments of an Unbelievable Past? Constructions of Provenance, Narratives of Forgery, University of Agder, 14-16 September, 2016, <https://www.academia.edu/28624547/Media_Dyna mics_and_Academic_Knowledge_Production_Tracing_the_Role_of_the_Media_in_the Gospel_of_Jesuss_Wife_Saga >, accessed on 10.04.19. 
combination thereof to speak to the matter together, in a more effective manner than any one method can on its own.

\section{$5 \quad$ Learning Patience}

Demonstrating that the Gospel of Jesus' Wife was a forgery was not something that could be accomplished overnight. It happened more quickly than it would have in earlier decades, thanks to the kinds of collaborations that have only become possible in the internet era. But speed is not a virtue in and of itself, especially if accuracy suffers as a result. ${ }^{26}$ Nor is the mere fact of eventually happening to be proven correct praiseworthy. ${ }^{27}$ In an age of increasing speed, and emphasis on streamlining and productivity with rapid results, it is crucial for scholars to learn (or remember) patience, and to make sure that we proceed - and draw conclusions - only as rapidly as rigorous adherence to scholarly (and/or journalistic) methods allows us to. It is better to proceed carefully and cautiously, and then once we have done our due diligence and feel that our conclusions are sound, we can utilize online platforms to disseminate our arguments and results almost immediately. Perhaps most important is that scholarly interaction online not reflect the penchant for unbending dogmatism that characterizes so much of what passes for conversation on the internet. As long as we are committed to remaining open to correction in light of new evidence and new arguments, the speed of our own individual contributions may matter significantly less. The study of the Gospel of Jesus' Wife saw some quick judgments in a variety of directions, but on the whole, the scholarly process worked well, inasmuch as arguments were made and evaluated, investigations were undertaken, information was shared, and ultimately academics and the general public were reached and persuaded by the disseminated results of those efforts.

A particularly exciting aspect of the Digital Humanities in our time is also its biggest pitfall, and the case of the Gospel of Jesus' Wife illustrates this point well. We have moved from a situation of scarcity of information to one of

26 See Caraher, William, "Slow Archaeology: Technology, Efficiency, and Archaeological Work," in: Walcek Averett, Erin, Gordon, Jody Michael, Counts, Derek B.(eds.), Mobilizing the Past for a Digital Future: The Potential of Digital Archaeology, Grand Forks: The Digital Press @ The University of North Dakota, 2016, 422-423, 436-437.

27 McGrath, James F., "Slow Scholarship : Do Bloggers Rush in Where Jesus' Wife Would Fear to Tread?" in: Burke, Tony (ed.), Fakes, Forgeries, and Fictions: Writing Ancient and Modern Christian Apocrypha: Proceedings from the 2015 York Christian Apocrypha Symposium, Eugene: Wipf and Stock, 2017, 326-340. 
overwhelming abundance. We have moved from a situation of painfully slow publication (think, for instance, of the Dead Sea Scrolls) to a situation in which a far greater number of ancient manuscripts are available in online repositories than the current number of scholars and students working in relevant areas could ever hope to translate. This might give a certain advantage to future forgers, who might be able to find and utilize (in other words, plagiarize) an obscure unpublished manuscript in creating a forgery, with or without making changes to the content to make it seem even more sensational and valuable.

But from another perspective, this ever-increasing abundance of digitized manuscripts also robs forgers of an advantage they might otherwise seem to have. Although we will always welcome new discoveries, we already have far more manuscripts that have already been discovered than we have time and academic personnel to translate them. There is enough to keep doctoral students in Syriac supplied with dissertation topics for countless decades to come, even assuming a major upturn in the number of students majoring in that field. There are so many exciting, newsworthy discoveries to be made among the current digitized manuscript collections of university libraries, that no one need feel compelled to give the benefit of the doubt to a private collector who approaches them with an unprovenanced manuscript or other artifact. ${ }^{28}$ Technological tools and digitization projects are speeding things up so significantly in comparison with the way things had to be done mere decades ago, that we can hopefully afford to take an extra day or two, if not indeed an extra few months, in order to run tests, and still make incredibly fast progress. The potential to have one's name associated with a spectacular find is not worth the risk of having one's name associated with a forgery. Unless one pulls something from the ground oneself, therefore, we not only can afford to be patient, but must be patient. If the members of the scholarly community are consistently patient in this manner, that too may serve to deter certain kinds of forgery. It should, at the very least, lessen the extent to which forgers receive validation of their productions from established authorities, which may in turn deprive them of the profit and/or media attention which they so eagerly seek, but do not deserve.

28 On the many issues related to private collections see further Mazza, Roberta, "Papyri, private collectors and academics: why the wife of Jesus and Sappho matter", Faces and Voices, $<$ https://facesandvoices.wordpress.com/2014/04/17/papyri-private-collectors-and-academics-why-the-wife-of-jesus-and-sappho-matter/>, accessed on 10.04.19 and Yates, Donna, "Some thoughts on the Hobby Lobby antiquities case," Anonymous Swiss Collector, 6 July 2017, <https://www.anonymousswisscollector.com/2017/o7/some-thoughts-on-thehobby-lobby-antiquities-case.html>, accessed on 10.04.19. 
As this study has hopefully established persuasively, there are a number of the important lessons that we can learn from the case of the Gospel of Jesus' Wife which are relevant to those working in the Digital Humanities. The Digital Humanities has a long history of emphasizing the need for collaboration across disciplinary lines, online, in order to draw the most reliable conclusions that we can, in the most expedient manner possible. The case of the Gospel of Jesus' Wife illustrates and provides supporting evidence for the fruitfulness of this approach. We can point to the difference between assumptions and conclusions offered from a single perspective about the Gospel of Jesus' Wife, and the convergence and clarity that became possible using varied approaches, collaboratively, through conversations on blogs, which were also used to disseminate those conclusions and from there picked up by media sources.

The case of the Gospel of Jesus' Wife also provides an opportunity to teach our students information fluency skills. We can do this by producing replicas to increase their understanding of manuscripts and other artifacts, the originals of which we cannot conveniently bring into the classroom when we teach. But we can also do this by showing them how scholarship works: that it is a practice of fallible human beings, who are capable of deceiving and being deceived, and capable of jumping to conclusions rather than patiently waiting for the scholarly process to run its course. Determining authenticity is not merely a case of running a specific scientific test. Nor is it a case of merely consulting an authority from Harvard University or anywhere else. Scholarship works through the pursuit of consensus, using specific tools and methods to reach our conclusions. For some students, the application of scholarly methods to the Bible poses special hurdles because of the importance of those texts within their faith traditions. Precisely by providing an example that is outside the canon (and for some, at odds with their faith tradition's teachings), the Gospel of Jesus' Wife provides a counterbalancing example which may be pedagogically useful, as students' own instincts to jump to conclusions about such a text may lead to reflection on how motives and biases can interfere with the course of scholarship. The Gospel of Jesus' Wife also highlights that, even when a conclusion that we jump to later proves correct, it is not a scholarly conclusion except when certain procedures are followed, and followed rigorously.

The preceding exploration of forgery and Digital Humanities also provides an opportunity for reflection on whether and to what extent the detection of forgeries is a good use of scholars' time. For those working in history and related fields, the study of authentic evidence should be our priority, rather than focusing on the evaluation of authenticity for its own sake. It may be that, in some instances, the skills required for the latter sort of task will be more those 
of an investigative journalist than those of a typical historian. Yet it may also be that, to some extent, learning those related yet distinct skills can prove useful for the study of history proper. Likewise, the collaborative crowdsourcing that typified the interaction between academics during the high points in the discussion of the Gospel of Jesus' Wife may also be transferrable to other matters that ought to be more central to our work than the detection of forgery. The development of new technological methods and processes as a result of collaboration between scientists and historical scholars suggests that involvement in forgery detection can itself lead to worthwhile products and results. We need to remember, however, that the Gospel of Jesus' Wife did not really tell us anything that we did not already know or at least suspect about views held in certain circles in the fourth century, and would never have told us something important about the historical Jesus even if it had proved authentic. Academics (individually and collectively) therefore need to reflect seriously on the question of how much of our time ought to be devoted to evaluation of authenticity in cases such as this one.

There are other lessons that can be drawn, and it is to be expected that the Gospel of Jesus' Wife may not be done teaching us new things. But there is much that we can already learn, including that what from one perspective was simply an unfortunate and often frustrating incident of forgery, also provided an opportunity, a test case, the positive outcomes from which speak to the power and importance of those approaches that fall under the heading of the Digital Humanities.

\section{References}

Askeland, Christian, “A Lycopolitan Forgery of John's Gospel,” NTS 61:3, July 2015, 314-334.

Askeland, Christian, "A Fake Coptic John and Its Implications for 'The Gospel of Jesus's Wife," TynBul 65, 2014, 1-10.

Bak, János M., Geary, Patrick J., Klaniczay, Gábor (eds.), National Cultivation of Culture: Manufacturing a Past for the Present. Forgery and Authenticity in Medievalist Texts and Objects in Nineteenth-Century Europe, 1, Leiden: Brill, 2014.

Bell, Suzanne, How to Identify a Forgery : A Guide to Spotting Fake Art, Counterfeit Currencies, and More, New York: Skyhorse Publishing, 2013.

Bennett, Bonnie K., 'Gospel of Jesus' Wife' Researcher Says Frenzy Distracts from Larger Issues," The Harvard Crimson, 11th of November 2016, <http://www.thecrim son.com/article/2016/11/11/papyrus-christianity-divinity-school/ $>$, accessed on 10.04.19. 
Bernhard, Andrew, "Postscript: A Final Note about the Origin of the Gospel of Jesus' Wife," NTS 63:2, 305-317.

Bernhard, Andrew, “The Gospel of Jesus' Wife: Summary of Coptic and English Evidence of Forgery," academia.edu: <https://www.academia.edu/31775308/The Gospel_of_Jesus_Wife_Summary_of_Coptic_and_English_Evidence_of_Forgery_ March_8_2017>, accessed on 10.04.19.

Bond, Sarah, "The Ethics Of 3 D-Printing Syria's Cultural Heritage," Forbes, 22nd of September2016,<https://www.forbes.com/sites/drsarahbond/2016/09/22/does-nycsnew-3d-printed-palmyra-arch-celebrate-syria-or-just-engage-in-digital-colonial ism/>, accessed March 19th, 2018.

Brown, Mark, “'New Rembrandt' to be unveiled in Amsterdam," The Guardian, <https:// www.theguardian.com/artanddesign/2016/apr/05/new-rembrandt-to-be-unveiledin-amsterdam $>$, accessed on 10.04.19.

Burleigh, Nina, Unholy Business: A True Tale of Faith, Greed and Forgery in the Holy Land, New York: Smithsonian Books/Collins, 2008.

Caraher, William, "Slow Archaeology: Technology, Efficiency, and Archaeological Work," in: Walcek Averett, Erin, Gordon, Jody Michael, Counts, Derek B.(eds.), Mobilizing the Past for a Digital Future: The Potential of Digital Archaeology, Grand Forks: The Digital Press @ The University of North Dakota, 2016, 421-441.

Craddock, Paul T., Scientific Investigation of Copies, Fakes and Forgeries, Amsterdam: Butterworth-Heinemann, 2009.

Ehrman, Bart D., Forgery and Counterforgery: The Use of Literary Deceit in Early Christian Polemics, Oxford University Press, 2012.

Goler, Sarah, et al., "Characterizing the Age of Ancient Egyptian Manuscripts through Micro-Raman Spectroscopy." Journal of Raman Spectroscopy 47.10, 2016, 1185-1193.

Heide, Martin, "The Moabitica and Their Aftermath: How to Handle a Forgery Affair with an International Impact," in: Lubetski, Meir and Edith (eds.), New Inscriptions and Seals Relating to the Biblical World: Society of Biblical Literature archaeology and biblical studies, Williston: Society of Biblical Literature, 2012, 193-241.

Jean-Baptiste, Patrick, L'affaire des fausses reliques: enquête au coeur des trafics de vestiges bibliques, Paris : Albin Michel, 2005.

Jordan Times, "Antiquities agency chief says Jordan Codices fake",Jordan Times, March 9th, 2017, <http://www.jordantimes.com/news/local/antiquities-agency-chief-saysjordan-codices-fake $>$, accessed on 10.04.19.

Krutzsch, Myriam, and Ira Rabin, "Material Criteria and their Clues for Dating," NTS 61:3, July 2015, 356-367.

Le Donne, Anthony, The Wife of Jesus: Ancient Texts and Modern Scandals, London: Oneworld, 2013 . 
Lenain, Thierry, “The Narrative Structure of Forgery Tales," in: Kila, Joris, Balcells, Marc (eds.), Heritage and Identity: Cultural Property Crime: An Overview and Analysis of Contemporary Perspectives and Trends, 1, Leiden: Brill, 2014, 39-60.

Lied, Liv Ingeborg, "Media Dynamics and Academic Knowledge Production: Tracing the Role of the Media in the Gospel of Jesus's Wife Saga," paper read at the conference Fragments of an Unbelievable Past? Constructions of Provenance, Narratives of Forgery, University of Agder, 14-16 September, 2016, <https://www.academia.edu/ 28624547/Media_Dynamics_and_Academic_Knowledge_Production_Tracing_the Role_of_the_Media_in_the_Gospel_of_Jesuss_Wife_Saga>, accessed on 10.04.19.

Liszewski, Andrew, "3D Printing and Scanning Can Now Produce Near Flawless Art Forgeries," Gizmodo, August 26th, 2013 <https://gizmodo.com/3d-printing-andscanning-can-now-produce-near-flawless-1201525111>, accessed on 10.04.19.

Mazza, Roberta, "Papyri, private collectors and academics: why the wife of Jesus and Sappho matter", Faces and Voices, <https://facesandvoices.wordpress.com/2014/ 04/17/papyri-private-collectors-and-academics-why-the-wife-of-jesus-and-sapphomatter/>, accessed on 10.04.19.

McGrath, James F., “Slow Scholarship : Do Bloggers Rush in Where Jesus' Wife Would Fear to Tread?" in: Burke, Tony (ed.), Fakes, Forgeries, and Fictions: Writing Ancient and Modern Christian Apocrypha:Proceedings from the 2015 York Christian Apocrypha Symposium, Eugene: Wipf and Stock, 2017, 326-340.

Meadows, David, "Oxyrhynchus and the First Apocalypse of James: Collection History Just Got Murkier," Rogue Classicism 12/13/2017, <https://rogueclassicism.com/2017/ 12/13/oxyrhynchus-and-the-first-apocalypse-of-james-collection-history-just-gotmurkier/>, accessed on 10.04.19.

Michelson, David A., "Syriaca.org as a Test Case for Digitally Re-Sorting the Ancient World," in: Clivaz, Claire, Dilley, Paul, Hamidović, David (eds.), Ancient Worlds in Digital Culture, Leiden: E.J. Brill, 2016, <http://discoverarchive.vanderbilt.edu/han dle/1803/8344>, accessed on 10.04.19, 59-85.

Moss, Candida, Baden, Joel, “Is Israel's Big New Find for Real?" The Daily Beast, nth of June 2016, <http://www.thedailybeast.com/articles/2016/11/o6/is-israel-s-big-newfind-a-hoax.html $>$, accessed on 10.04.19.

Nickell, Joe, Real Or Fake: Studies In Authentication. Lexington: The University Press of Kentucky, 2009, eBook Collection (EBscohost), Web, accessed November 11, 2016.

Nongbri, Brent, "Provenance and The Oxyrhynchus Papyri," Variant Readings 12/13/2017, $<$ http://brentnongbri.com/2017/12/13/provenance-and-the-oxyrhynchus-papy $\mathrm{ri} />$, accessed on 10.04.19.

Parker, Heather Dana Davis, "Forging Ancient Texts," The Ancient Near East Today, vol. 4, $\mathrm{n}^{\circ} 10$, October 2016, <http://www.asor.org/anetoday/2016/10/o6/forging-an cient-texts/>, accessed on 10.04.19. 
Rabinowitz, Adam, "The Work of Archaeology in the Age of Digital Surrogacy," in: Olson, Brandon R., Caraher, William (eds.), Visions of Substance: ${ }_{3} D$ Imaging in Mediterranean Archaeology, Grand Forks: The Digital Press at The University of North Dakota, 2015, 27-42.

Rollston, Christopher, "Navigating the Epigraphic Storm: A Palaeographer Reflects on Inscriptions from the Market," Near Eastern Archaeology 68, $\mathrm{n}^{\circ}$ 1/2, March - June 2005, 69-72.

Ruthven, K.K., Faking Literature, Cambridge: Cambridge University Press, 2001.

Sabar, Ariel, "The Unbelievable Tale of Jesus' Wife," The Atlantic, July/August 2016, $<$ https://www.theatlantic.com/magazine/archive/2016/07/the-unbelievable-taleof-jesus-wife/485573/>, accessed <http://www.asor.org/anetoday/2016/10/o6/forg ing-ancient-texts/>.

Schroeder, Caroline, "On Palmyra and ${ }_{3} \mathrm{D}$ Modeling Cultural Heritage in the Middle East," Early Christian Monasticism in the Digital Age 6/12/2016, <http://earlymonas ticism.org/2016/o6/12/on-palmyra-and-3d-modeling-cultural-heritage-in-the-mid dle-east/>, accessed on 10.04.19.

Schroeder, Caroline, "More on Social Networks and Provenance," Early Christian Monasticism in the Digital Age 6/16/2016, <http://earlymonasticism.org/2016/o6/16/ social-networks/ $>$, accessed on 10.04.19.

Schroeder, Caroline, "Provenance Provenance Provenance," Early Christian Monasticism in the Digital Age 6/16/2016, <http://earlymonasticism.org/2016/o6/16/provenanceprovenance-provenance/>, accessed on 10.04.19.

Schroeder, Caroline, "Institutional Responsibilities," Early Christian Monasticism in the Digital Age 6/23/2016, <http://earlymonasticism.org/2016/06/23/on-institutionalresponsibilities-and-on-gender-final-thoughts-on-the-g-of-jesus-wife/>, accessed on 10.04.19.

Schroeder, Caroline, "Gender and the Academy Online: The Authentic Revelations of the Gospel of Jesus' Wife," in: Burke, Tony (ed.), Fakes, Forgeries, and Fictions: Writing Ancient and Modern Christian Apocrypha: Proceedings from the 2015 York Christian Apocrypha Symposium, Eugene: Wipf and Stock, 2017, 304-325.

Stierlin, Henri, Le Buste de Néfertiti. Une imposture de l'égyptologie?, Gollion: Infolio, 2009.

Yates, Donna, "Some thoughts on the Hobby Lobby antiquities case," Anonymous Swiss Collector, 6 July 2017, <https://www.anonymousswisscollector.com/2017/07/somethoughts-on-the-hobby-lobby-antiquities-case.html>, accessed on 10.04.19. 